\title{
A FILOSOFIA NO ENSINO MÉDIO: DA INSTITUIÇÃO DA DISCIPLINA AO DESAFIO DA EXPERIÊNCIA EDUCATIVA NO MATERIAL DIDÁTICO
}

\author{
Tânia Rodrigues Palhano ${ }^{1}$ \\ Maria das Graças de Almeida Baptista ${ }^{2}$
}

\begin{abstract}
Resumo
A partir de 2008, com a instituição do Ensino de Filosofia como disciplina no Ensino Médio, são suscitadas questões acerca dos materiais didáticos que envolvem discussões sobre a forma de organização dos conteúdos. O presente estudo analisa a legislação que incide na obrigatoriedade do ensino de filosofia no Ensino Médio, relacionando-a à prática desta atividade no Estado da Paraíba. O objetivo é investigar os materiais didáticos de filosofia, situando-os no contexto de uma educação voltada para a formação profissional ou o ingresso no ensino superior. A metodologia consiste na investigação sobre a legislação; na experiência filosófica no contexto escolar, a partir do conceito de experiência na educação em Dewey; e na análise dos materiais didáticos de filosofia no Ensino Médio no Estado da Paraíba. A instituição da Filosofia, convertida em conhecimento escolar, visando uma educação crítica, libertadora e criadora, deve possibilitar ao estudante a autonomia de pensar e agir.
\end{abstract}

Palavras-chave: Ensino de filosofia; Legislação educacional; Prática educativa

\section{THE PHILOSOPHY IN HIGH SCHOOL FROM THE INSTITUTION OF DISCIPLINE TO THE CHALLENGE OF EDUCATIONAL EXPERIENCE IN DIDACTIC MATERIAL}

\footnotetext{
${ }^{1}$ Tânia Rodrigues Palhano, Doutora em Educação (UFPB) e Pós-Doutora em Educação (UNICAMP), professora do Programa de Pós-Graduação em Educação (PPGE/CE) e dos Cursos de Licenciatura da Universidade Federal da Paraíba. Email: taniarpalhano@gmail.com

${ }^{2}$ Maria das Graças de Almeida Baptista, Doutora em Educação e Pós-Doutora em Educação (UNICAMP), professora do Programa de Pós-Graduação em Educação (PPGE/CE) e dos Cursos de Licenciatura da Universidade Federal da Paraíba. Email: mgabaptista2@yahoo.com.br
} 


\begin{abstract}
From 2008, with the introduction of Philosophy's Teaching as high school discipline, are raised questions about the didactic materials that involve discussions about the form of organization of contents. The present study examines the legislation that focuses on mandatory teaching of philosophy in high school, relating to the practice of this activity in the State of Paraíba. The objective is to investigate the didactic materials of philosophy, placing them in the context of an education focused on vocational training or the entry into higher education. The methodology consists in the research about the legislation; in the philosophical experience in school context from the concept of education's experience in Dewey; and in the analysis of the didactic materials of philosophy in high school in the State of Paraíba. The institution of Philosophy, converted into scholarly knowledge, aiming at a critical, liberating and creative education, must allow the student the autonomy of think and act.
\end{abstract}

Keywords: Philosophy's teaching; Educational legislation; Educational practice

\title{
LA FILOSOFÍA EN LA ENSEÑANZA DE SEGUNDO GRADO: DE LA INSTITUCIÓN DE LA ASIGNATURA AL DESAFÍO DE LA EXPERIENCIA EDUCATIVA EN EL MATERIAL DIDÁCTICO
}

\section{Resumen}

A partir de 2008, con la institución de la Enseñanza de Filosofía como asignatura en la Enseñanza de segundo grado, son suscitadas cuestiones acerca de los materiales didácticos que envuelven discusiones acerca da forma de organización de los contenidos. El presente estudio analiza la legislación que incide en la obligatoriedad de la enseñanza de filosofía en la Enseñanza de segundo grado, relacionándola a la práctica de esta actividad en la Provincia de Paraíba. El objetivo es investigar los materiales didácticos de filosofía, ubicándolos en el contexto de una educación direccionada a la formación profesional o al ingreso en la enseñanza superior. La metodología consiste en la investigación sobre la legislación; en la experiencia filosófica en el contexto escolar a partir del concepto de experiencia en la educación en Dewey; 
y en el análisis de los materiales didácticos de filosofía en la Enseñanza de segundo grado en la Provincia de Paraíba. La institución de la filosofía,convertido en el conocimiento escolar, con el objetivo de una educación crítica, liberadora y creativa, debería permitir a la autonomía de los estudiantes de pensar y de actuar.

Palabras claves: Enseñanza de filosofia; Legislación educacional; Práctica educativa

\section{INTRODUÇÃO}

O presente trabalho é fruto de pesquisa junto ao tema Filosofia no Ensino Médio, mais especificamente no Estado da Paraíba. O retorno da filosofia nesse nível de ensino traz para o debate a velha, mas ainda hoje pertinente, máxima marxiana da $11^{\text {a }}$ Tese contra Feuerbach, "os filósofos se limitaram a interpretar o mundo de diferentes maneiras; o que importa é transformá-lo" (MARX, 1996, p. 14). A referida pesquisa atualiza essa máxima relacionandoa ao ensino de filosofia.

$\mathrm{Na}$ perspectiva deweyana, que orienta o presente estudo, há um esforço em tornar a experiência não somente uma ação imediata sobre o ambiente, mas uma experiência educativa, inteligente, em que o pensamento sistemático, com o domínio do método científico, torna-se socialmente útil ao projetar consequências futuras. Portanto, fugindo de uma filosofia tradicionalista e contemplativa, Dewey propõe uma filosofia baseada na ação que possibilita uma modificação tanto na situação, como no indivíduo e, consequentemente, na sociedade.

Dessa forma, logo de início, essa tarefa impõe, na atualidade, pelo menos dois questionamentos: por que a filosofia, após ter sido banida como disciplina das escolas durante a ditadura militar, percorre o caminho do caráter de conhecimento ao status de disciplina no Ensino Médio? Na essência, essa obrigatoriedade conduz a mais uma interpretação do mundo ou à sua transformação?

Nesse artigo apresenta-se uma etapa dessa pesquisa, qual seja, a investigação sobre a legislação que incide na obrigatoriedade do ensino de filosofia no Ensino Médio, relacionandoa à implantação dessa prática no Estado da Paraíba, especificamente em relação aos materiais didáticos.

O ensino de filosofia em nível médio carrega mais de meia década de experiência ao chegar à escola brasileira após sua obrigatoriedade como componente curricular. Antes disso, a filosofia tinha o caráter de conhecimento interdisciplinar. Com a obrigatoriedade, a filosofia 
vem passando por um processo de consolidação institucional, representada pela presença constante de demanda e reflexões filosóficas de variado teor.

O ensino de filosofia como conhecimento escolar surge historicamente como suporte de construção da reflexão pedagógica e da sua própria crítica filosófica, como reconstrução do pensar racional desenvolvido desde os gregos e ressaltada na modernidade com o racionalismo e o empirismo.

A filosofia na educação como conhecimento escolar consiste na busca em conhecer e compreender não apenas o significado de algo, mas também as questões que despertam curiosidade ao ser humano. Questiona-se se a forma e a organização dos conteúdos nos materiais didáticos, desenvolvidos para esse nível de ensino, favorecem esse conhecimento e essa curiosidade ou restringe-se a situar os jovens no contexto de uma formação de preparação para o trabalho.

O foco é a compreensão da filosofia na educação, mais especificamente acerca de concepções, valores, decisões, bem como emissão de juízos, que servirão de fundamentos aos debates em que o ensino de filosofia, no momento atual, se confronta. Entende-se que, na conversão do saber filosófico em conhecimento escolar, os conteúdos de filosofia, no ensino médio, devem ser apresentados aos alunos em materiais didáticos expressos em temas, história, conceitos, que aliados a métodos didáticos específicos, possibilitem ao estudante a apropriação de um conteúdo filosófico significativo na leitura de sua realidade.

A metodologia desse estudo consiste em três momentos: a investigação sobre a legislação; a experiência filosófica no contexto escolar a partir do conceito de experiência na educação em Dewey; culminando com a análise dos materiais didáticos de filosofia no Ensino Médio no estado da Paraíba.

\section{O ENSINO DE FILOSOFIA EM NÍVEL MÉDIO: DOS CONHECIMENTOS À DISCIPLINA}

Com a aprovação do Parecer no 22/2008 e da Resolução nº 1/2009, ambos pela Câmara de Educação Básica (CEB), do Conselho Nacional de Educação (CNE), conclui-se o processo de inclusão da Filosofia e da Sociologia como disciplinas obrigatórias nos currículos do Ensino Médio.

A discussão que resultou nessa Resolução, segundo o Parecer CNE/CEB nº 38/2006, tem início, oficialmente, em fevereiro de 2006, quando a Câmara de Educação Básica promove uma 
reunião para a qual foram convidados "sociólogos, professores de Filosofia e de Sociologia, representantes de entidades, estudantes e outros profissionais", com o intuito de discutir o tema Alteração das Diretrizes Curriculares Nacionais para o Ensino Médio/inclusão de componentes curriculares obrigatórios de Filosofia e Sociologia. Dessa reunião resultou um documento encaminhado ao CNE, pelo Secretário de Educação Básica do MEC, sobre as "Diretrizes Curriculares das disciplinas de Sociologia e Filosofia no Ensino Médio”. (BRASIL, 2006a, p. 2).

O Parecer aponta que, historicamente, essa discussão inicia-se "poucos meses após a promulgação" da Lei de Diretrizes e Bases da Educação Nacional, com o Parecer CNE/CEB nº 5/97, que trata da "Proposta de Regulamentação" da LDB e inclui, além de outros pontos, objetivos de natureza ético/social que "dizem respeito a valores fundamentais ao interesse social, direitos e deveres dos cidadãos, envolvendo respeito ao bem comum e à ordem democrática, como fundamentos da sociedade", que abrangeriam "formação de atitudes, preparação para o trabalho, para a cidadania e para a ética nas relações humanas" (BRASIL 2006a, p. 3-4) (grifo nosso).

O Parecer, inicialmente, reitera "a importância e o valor da Filosofia e da Sociologia para um processo educacional consistente e de qualidade na formação humanística de jovens que se deseja sejam cidadãos éticos, críticos, sujeitos e protagonistas"; e ressalta a conformidade dessas orientações com a própria LDB, uma vez que esses conhecimentos são apontados, assim como na LDB, como "necessários ao exercício da cidadania" (art. 36); ao "aprimoramento como pessoa humana, incluindo a formação ética e o desenvolvimento da autonomia intelectual e do pensamento crítico" (art. 35), à "difusão de valores fundamentais ao interesse social, aos direitos e deveres dos cidadãos, de respeito ao bem comum e à ordem democrática" (art. 27). Além desses aspectos, o Parecer acentua a crescente inclusão dessas disciplinas nos currículos da rede pública e particular "como resultado de uma persistente mobilização de amplos setores ligados à educação, que defendem a Sociologia e a Filosofia no contexto dos esforços de qualificação do Ensino Médio no Brasil” (BRASIL, 2006a, p. 2-3).

O Parecer contrapõe-se às Diretrizes Curriculares Nacionais para o Ensino Médio (DCNEM) ao afirmar que há uma base nacional comum dos currículos do Ensino Médio (art. 10), organizada em três áreas de conhecimento: linguagens e códigos; ciências da natureza e matemática; e ciências humanas, que deveriam ser tratados interdisciplinar e contextualizadamente, e que deveriam incluir, entre esses conhecimentos, os de Filosofia e Sociologia “necessários ao exercício da cidadania” (BRASIL, 2006a, p. 5-6) (grifo nosso). 
Por outro lado, o Parecer confronta as DCNEM com os Parâmetros Curriculares Nacionais para o Ensino Médio (PCNEM), destacando que apesar dos PCNEM serem "subsídios valiosos”, "não são normas, nem são de aplicação obrigatória, como o são as DCNEM" (BRASIL, 2006a, p. 6) (grifo nosso).

O Parecer também ressalta que, de acordo com as Orientações Curriculares do Ensino Médio (BRASIL, 2006b), os PCN “dão tratamento disciplinar à Filosofia como, de modo singular, defendem sua obrigatoriedade", entretanto, prossegue o documento, "é evidente que, não podendo tornar obrigatório o que a LDB apenas faculta, os PCN tomam a defesa da área e recomendam a presença obrigatória de um profissional de Filosofia no Ensino Médio”. Quanto ao formato de disciplina, o documento conclui que, apesar das escolas terem "autonomia quanto à sua concepção pedagógica e à formulação de sua correspondente proposta curricular", poucas escolas "adotam concepções mais flexíveis e inovadoras, que a LDB permite e as DCNEM incentivam”, uma vez que há “dúvidas quanto à capacidade de efetivação do prescrito na LDB e nas DCNEM". Os professores “comprometidos com o desenvolvimento do programa de suas disciplinas, dificilmente terão condições de dar tratamento interdisciplinar e contextualizado aos necessários conhecimentos de Filosofia e Sociologia”, assim como a outros conhecimentos "tão requeridos para o exercício da cidadania e para atender ao dever de 'vincular-se ao mundo do trabalho e à prática social" (BRASIL, 2006a, p. 7) (grifos nossos).

Nesse sentido, o documento reafirma que "os conteúdos, as metodologias e as formas de avaliação [devem ser] organizados de tal forma que, ao final do Ensino Médio, o educando demonstre, entre outros, o domínio dos conhecimentos de Filosofia e de Sociologia necessários ao exercício da cidadania", e apresenta a seguinte questão: “como garantir a eficácia dessa diretriz, se não forem efetivados processos pertinentes de ensino e aprendizagem que propiciem esses conhecimentos"? E conclui indicando que a Resolução CNE/CEB n 3/98, que instituiu as DCNEM, seja revisitada, considerando seu caráter orientador, e propõe, desde já, sua alteração no sentido de que nas escolas que adotem uma "organização curricular estruturada por disciplinas, deverão ser incluídas as de Filosofia e Sociologia”, diferentemente das que adotam uma organização flexível que "deverão assegurar tratamento interdisciplinar e contextualizado, visando ao domínio de conhecimentos de Filosofia e Sociologia necessários ao exercício da cidadania" (BRASIL, 2006a, p. 7-9) (grifos nossos).

Até aqui, os conteúdos de Filosofia e Sociologia eram tratados como "conhecimentos". A Lei no 11.684/2008 altera o art. 36 da LDB "para incluir a Filosofia e a Sociologia como disciplinas obrigatórias nos currículos do ensino médio", entretanto, mantém a redação do art. 
35, em que o Ensino Médio, enquanto "etapa final da educação básica”, tem como finalidade: a "preparação básica para o trabalho e a cidadania", com vista a "se adaptar com flexibilidade a novas condições de ocupação ou aperfeiçoamento posteriores"; o "aprimoramento como pessoa humana", o que inclui a "formação ética e o desenvolvimento da autonomia intelectual e do pensamento crítico"; e a "compreensão dos fundamentos científico-tecnológicos dos processos produtivos, relacionando a teoria e a prática" em cada disciplina. Sem, entretanto, especificar como ocorreria essa relação teoria e prática.

Nesse caso, reafirma-se a redação desenvolvida na Lei $\mathrm{n}^{\circ}$ 11.684/2008, que determina a obrigatoriedade das disciplinas filosofia e sociologia "em todas as séries do Ensino Médio", e denuncia-se, conforme explícito no PCNEM, a ausência de outros conhecimentos/disciplinas que poderiam compor a formação a nível Médio: “outros conhecimentos das Ciências Humanas que consideramos fundamentais para o Ensino Médio. Trata-se de referências a conhecimentos de Antropologia, Política, Direito, Economia e Psicologia” (BRASIL, 1999, p. 4).

A inclusão da filosofia enquanto disciplina, e não mais como conhecimento, entretanto, parece não alterar o seu papel na formação dos indivíduos e sua disposição científico-adaptativa para o mundo do trabalho e o "exercício da cidadania", destacando o bem comum e a ordem democrática, como "fundamentos da sociedade", formação de atitudes e a ética nas relações humanas de perspectiva liberal-democrática, em contradição com o "desenvolvimento da autonomia intelectual e do pensamento crítico". Além do que parece não se debruçar sobre as contradições sociais com vista à construção de novos sujeitos e uma nova sociedade, capazes de ascender a "uma verdadeira concepção - filosófica - da práxis" (VÁZQUEZ, 1968, p. 16).

Enfim, o Parecer CNE/CEB no 38/2006 afirma que "se a escola tem autonomia para desenvolver na própria concepção pedagógica", ela tem "obrigação de coerência nessa concepção, bem como no seu planejamento, na sua organização e na sua execução". Nesse sentido, as escolas “devem oferecer condições reais para sua efetivação, com professores habilitados em licenciaturas que concedam direito de docência desses componentes, além de outras condições, como, notadamente, acervo pertinente nas suas bibliotecas" (BRASIL, 2006a, p. 8).

Vale salientar aqui dois conceitos/objetivos recorrentes nos textos acima referidos: preparação para a cidadania e preparação para o trabalho. Tais conceitos, aliados à formação de atitudes e a preparação para a ética, são apresentados desde o Parecer CNE/CEB nº 5/97, como objetivos de "natureza ético/social", que "dizem respeito a valores fundamentais ao interesse 
social, direitos e deveres dos cidadãos, envolvendo respeito ao bem comum e à ordem democrática, como fundamentos da sociedade" (BRASIL, 1997, p. 4).

Como interesse social, direitos e deveres, bem comum, e ordem democrática são apresentados como algo já construído, e não como um vir-a-ser na prática social, a expressão "preparação para a cidadania" pode representar uma inculcação acerca dos direitos e deveres necessários ao interesse e à ordem vigente. Por conseguinte, "preparação para o trabalho" pode representar, além dessa apropriação, o domínio pragmático de conhecimentos e técnicas necessários ao mundo do trabalho, inclusive com o aumento do "ano letivo para 200 dias de trabalho efetivo, excluído o tempo reservado aos exames finais" (BRASIL, 1997, p. 3). Essa alteração, considerada "um avanço", termina por formar um excedente de reserva necessário e adequadamente dócil ao capital (BAPTISTA, 2012) (grifo nosso).

\section{A EXPERIÊNCIA DA FILOSOFIA NO CONTEXTO ESCOLAR}

O ensino de filosofia, ao ser convertido em conhecimento escolar, tem incidido mais nos meios do que nos fins. Embora o professor tenha a função de mediar e não de ditar aos alunos quais devem ser suas filosofias de vida, é fundamental a experiência interativa entre alunos e docente. Cabe aqui questionarmos que tipo de experiência filosófica está se apresentando ao jovem nos primeiros contatos com tais conteúdos.

$\mathrm{Na}$ busca da compreensão acerca do conceito de experiência, destaca-se a teoria da experiência em John Dewey. A experiência, conceito básico da filosofia deweyana, significa a interação do organismo e do meio ambiente que redunda em alguma adaptação para melhor utilização deste meio ambiente. Segundo o autor, no plano humano, além da escolha, preferência e seleção, acrescenta-se a reflexão, o conhecimento e a reconstrução da experiência. E a experiência humana é dada pela acumulação muitas vezes secular de tudo que o homem sofreu, conheceu e amou (TEIXEIRA, 1973, p.14).

O conhecimento se dá pelo método experimental do pensar, o pensamento tem utilidade, ele é útil porque nos dá a possibilidade da previsão de consequências futuras, baseada na observação completa das condições presentes. Assim, a experiência, em Dewey, é uma verdadeira interação do indivíduo com o ambiente. Por um lado, deve ser um processo contínuo e sempre presente e, por outro, só se justifica se tiver repercussão no futuro. 
Tal perspectiva de experiência denota a propositura de uma prática reflexiva de ações e projeções que apontam na direção do futuro. $\mathrm{O}$ autor, portanto, empreende o uso de uma regra de ação específica de base moral, para o alcance do benefício individual e social.

Quando experimentamos algo, agimos sobre esse algo, em seguida sofremos ou sentimos as consequências dessa ação. A conexão dessas duas fases da experiência mede o fruto ou o valor da mesma. A simples atividade não constitui experiência (DEWEY, 1959, p. 152).

A experiência em Dewey por ser uma verdadeira interação do indivíduo com o ambiente, não é uma mera atividade sem consequências e sim uma verdadeira vivência, por meio da qual se produz uma modificação, não só na situação, mas também no indivíduo que viveu a experiência (PALHANO, 2011).

Sobre a relação entre experiência e educação, Teixeira (1973, p. 17) aponta que a experiência educativa é a experiência inteligente, em que participa o pensamento, através do qual se vêm a perceber relações de continuidade antes não percebidas. Para Dewey, a educação, através da ciência, busca melhorar a inteligência e, consequentemente, a qualidade da experiência. Desse modo, acreditava que o homem poderia progredir através do uso de sua inteligência, uma faculdade que proveria usos criativos para suas experiências prévias. Isso ajudaria na solução dos novos problemas do presente. As implicações dessas concepções na educação, conforme Rossi (1982, p. 64), são claras: uma verdadeira educação deveria dar aos estudantes a prática na solução de problemas através do uso de suas experiências passadas, ao invés de simplesmente enfatizar a reprodução mnemônica do conhecimento previamente gerado por outra pessoa.

Quando Dewey (1971, p. 13) fala de experiência, historicamente quer significar que, com o domínio do método científico, a qualidade da experiência melhorou. Mas não quer dizer que toda experiência, mesmo tendo uma conexão orgânica com a educação, seja educativa: “algumas experiências são deseducativas. É deseducativa toda experiência que produza o efeito de parar ou destorcer o crescimento para novas experiências posteriores".

A experiência, segundo o autor, pode ser imediatamente agradável e, entretanto, concorrer para atitudes descuidadas e preguiçosas, atuando sobre a qualidade das futuras experiências. Por outro lado, as experiências podem ser tão desconexas e desligadas umas das outras que, embora agradáveis e mesmo excitantes, não se articulam cumulativamente (DEWEY, 1971, p. 14).

Ao estabelecermos uma correspondência entre o conceito de prazer e interesse ao de experiência, destacamos em Aristóteles (2008, p. 223) que o prazer completa as atividades, mas 
“como explicar, então, o fato de ninguém sentir prazer continuamente? Será que ficaríamos enfastiados?" O próprio autor responde que: “o fato é que nenhum ser humano é capaz de uma atividade contínua, e essa é a razão de não ser contínuo também o prazer”.

A atividade filosófica como uma experiência prazerosa para os jovens educandos, cercados pelas necessidades de consumo impostas pelo mercado capitalista e impelidos a resultados imediatos e de caráter de utilidade, é um exercício de superação. Por sua vez, a atitude do filosofar supõe a aquisição de instrumentos conceituais para transformar a experiência vivida numa experiência compreendida, seja examinando os pressupostos das ciências, da técnica, das artes, seja avaliando a ação do político, a proposta pedagógica de uma escola, as justificativas de um comportamento, quaisquer que sejam, enfim, os projetos humanos.

Não se trata, portanto, de um mero exercício acadêmico, pelo qual o aluno adquire um "verniz”, torna-se "culto" ou mais habilidoso nas artes da argumentação. O ensino da filosofia "supõe um compromisso com a vida, para que possa se recuperar, em um mundo por demais pragmático, o que os gregos já chamavam de capacidade de admirar-se, ou seja, do espanto diante do óbvio, do corriqueiro, das certezas sedimentadas" (ARANHA; MARTINS, 2009, p. 118).

Educar para a reflexão e o debate é, portanto, aspirar à construção da sociedade pluralista, baseada na formação da identidade autônoma e crítica, e ao mesmo tempo na capacidade de admitir e aceitar diferenças.

A perspectiva de um ensino de filosofia comprometido com a autonomia da capacidade de pensar e agir é a de que o jovem, ao ingressar no Ensino Médio e ao ter contato com a filosofia, desenvolva experiências de pensamento, como o raciocínio lógico, a criatividade, a reflexão, aprimorando sua capacidade de pensar, tanto ao identificar como produzir conceitos, fazer experiência da crítica ao perceber a sua própria vida, desenvolver uma atitude dialógica com o outro e com o mundo, aprender uma atitude interrogativa ao pensar o mundo e a si mesmo.

Nesse sentido, cabe-se perguntar: como trabalhar o saber filosófico sem a característica fundante da corrida para o mercado de trabalho? Como favorecer aos jovens conhecimentos que possibilitem o saber reflexivo, para a compreensão da realidade e da própria concepção de mundo? Assim como, se os conteúdos desenvolvidos na formação dos jovens discentes que estão tendo acesso aos conhecimentos da linguagem filosófica, conceitos, temas e história, 
tratados no livro didático adotado, têm favorecido a experiência educativa quanto a aspectos específicos da reflexão filosófica.

\section{O ENSINO DE FILOSOFIA NO NÍVEL MÉdIO NO ESTADO DA PARAÍbA: O LIVRO DIDÁTICO EM QUESTÃO}

Na Paraíba, a filosofia se consolida como uma disciplina efetiva, na esfera pública estadual do ensino médio, no início do ano letivo de 2009, com a realização de concurso para as disciplinas Filosofia e Sociologia. No segundo semestre desse ano, os professores se mobilizam e é formada uma comissão para tratar de assuntos referentes à introdução do ensino de filosofia, tais como, elaboração de plano de curso, escolha de livro didático e outras questões pertinentes. Vale salientar que o ensino de filosofia atinge tão somente o $1^{\circ}$ ano do Ensino Médio, tendo em vista a urgência do caráter de obrigatoriedade e a falta de recursos humanos, estendendo-se às séries subsequentes a cada ano.

Inicialmente, a Secretaria da Educação apresenta nove títulos de livros à comissão, sendo escolhidos três: "Filosofando: introdução à filosofia", de Maria Lúcia de Arruda Aranha e Maria Helena Pires Martins (2009), "Vivendo a filosofia", de Gabriel Chalita (2009) e "Filosofia construindo o pensar", de Dora Incontri e Alessandro Cesar Bigheto (2008), este último adotado pela Secretaria de Educação do Estado. O livro chega às escolas em 2010. Até então, o professor de filosofia utilizava-se de diversos materiais didáticos como apostilas, textos, vídeos e músicas. Vale ressaltar que este livro não é escrito por filósofos egressos de Cursos de Filosofia, mas por um jornalista com doutorado em Filosofia da Educação e um pedagogo com mestrado em Educação, na linha de História e Filosofia.

O livro é composto por três volumosas partes, distribuídas em 448 páginas, a serem trabalhadas ao longo dos três anos do Ensino Médio. Além da Introdução, apresenta doze capítulos temáticos que mesclam história, poesia, música, artes plásticas e fotografia, além de citações de teorias de diversos filósofos; uma parte histórica com seis capítulos de história da filosofia; e um dicionário de filósofos, em que são expostas biografias e principais obras de cento e trinta e três pensadores da filosofia.

$\mathrm{Na}$ Introdução, os autores expõem a dificuldade de separar a Filosofia em temas. Afirmam que, uma vez que "um tema toca o outro e a maioria dos pensadores tratou de quase todos os assuntos", o importante é saber como um tema é tratado por um determinado filósofo, ou seja, é a apropriação da tradição do conhecimento filosófico, com o intuito de que o leitor/leitora 
seja capaz de pensar por si próprios os problemas centrais da existência (INCONTRI; BIGHETO, 2009, p.7).

Ao final de cada capítulo temático são apresentadas atividades de estudos dos textos e demais tarefas com auxílio de músicas; telas ou quadros de artistas plásticos, filmes, jornais, pesquisas científicas, produção de artes, poesia, teatro, internet, e outras referências bibliográficas.

Quanto à arte, o livro tem um design moderno com imagens significativas, retratando a arte em vários aspectos, como na serigrafia, na pintura, na fotografia e na música, apresentando aos jovens costumes de diversas culturas.

Entretanto, enquanto material orientador das aulas de filosofia, o livro impõe algumas dificuldades ao professor, muitos deles oriundos de cursos de graduação, cuja tônica se assenta no bacharelado, refletindo o veio acadêmico do pesquisador e apresentando deficiências em didática e no manuseio de materiais didáticos para a vivência escolar do ensino, em especial, no nível médio.

Um dessas dificuldades refere-se à relação conteúdo e carga horária semanal. Por um lado, os capítulos são extensos, o que requer do professor conhecimento teórico e didático, e esforço para programar a divisão e o desenvolvimento dos conteúdos no transcorrer dos três anos do ensino médio. Por outro, como os exercícios são apresentados somente ao final de cada capítulo, caberá ao professor planejar atividades de revisão para cada aula desenvolvida.

Dentre as atividades apresentadas ao final de cada capítulo, destaca-se o capítulo 1 Filosofia, o que é? Como, por que e para quê? -, que visa avaliar os alunos acerca da compreensão sobre as diversas definições de filosofia, o que sugere uma atuação direta ao educando com os conteúdos da filosofia. Nesse sentido, a análise baseia-se no conceito de experiência em Dewey e de prazer em Aristóteles.

Além da leitura do capítulo e do texto "Diretrizes do pensamento filosófico", de Bochenski, é sugerido aos alunos discutir o sentido da filosofia na música "Filosofia", de Noel Rosa, apresentada no livro, e criar uma letra musical sobre o significado que apreenderam sobre filosofia, provocando a criatividade dos alunos.

Percebe-se que nas atividades elencadas ao final de cada capítulo, são expostos outros recursos de aprendizagem como músicas, filmes, poemas, jornais, recursos da internet, visando a produção de textos, pintura de quadros, elaboração de mapas conceituais, criação de paródias, a partir de letras de músicas, entre outros. No campo de saberes filosóficos, tais atividades possibilitam o desenvolvimento de atividades diversas na experiência do aluno, enquanto 
participante ativo do processo de aprendizagem, deste modo a avaliação não fica apenas restrita à verificação dos conteúdos assimilados.

Sobre a relação entre experiência e educação, Teixeira (1973, p. 17) nos explica que a experiência educativa é a experiência inteligente, em que participa o pensamento, através do qual se vêm a perceber relações de continuidade antes não percebidas. Conforme exposto anteriormente, Dewey relaciona a experiência à educação, no sentido de que a educação melhora, pela inteligência, a qualidade da experiência.

Nesse sentido, o livro "Filosofia - Construindo o Pensar", ao final de cada capítulo temático, apresenta uma diversidade de atividades que ultrapassa o processo de aprendizagem para além do texto didático, como único suporte para a organização mental e memorização dos conteúdos. Entretanto, para Rodrigo (2009), as atividades de aprendizagem podem adquirir, simultaneamente, caráter avaliativo e auto avaliativo e, inversamente, exercícios de avaliação devem ser explorados também na perspectiva das oportunidades que oferecem à aprendizagem.

Os materiais didáticos de filosofia, segundo a autora, são apresentados em formas comuns de organização, ressaltando duas abordagens básicas: a sistemática e a histórica. A primeira tem sua "disposição segundo uma ordenação estabelecida com base nas partes em que o saber filosófico é dividido", e a abordagem histórica apresenta uma exposição cronológica do pensamento filosófico (RODRIGO, 2009, p. 42).

Para a autora, a abordagem sistemática deve estar articulada com a problematização do tema abordado ou análise crítica, em oposição a uma sistematização que não permita o movimento do pensamento. Por sua vez, a abordagem histórica deve apresentar o passado reposto a partir das indagações do presente, uma vez que permitir "o diálogo crítico com a tradição se constitui como uma das formas de filosofar-se na contemporaneidade" (RODRIGO, 2009, p. 49).

Mas, por que se deve buscar uma postura indagadora sobre o sentido do real? Por que a necessidade de buscar respostas? Estas são questões que têm na história da filosofia o seu referencial, independente do conteúdo programático que se exponha nas aulas de filosofia ou das afinidades do professor.

O ensino de filosofia, como disciplina escolar, ao tempo em que instiga um pensar organizado, sistemático, para melhor compreensão da realidade, deve apresentar o aspecto prazeroso a partir da reflexão sobre os conteúdos de filosofia, como experiência filosófica, e seu diálogo com o currículo escolar. Dewey, em sua teoria da experiência, ressalta que o conhecimento ocorre pelo método experimental do pensar, o pensamento tem utilidade, ele é 
útil por nos dar a possibilidade da previsão de consequências futuras, baseada na observação das condições presentes.

\section{DA LEGISLAÇÃO À PRÁTICA DO ENSINO DE FILOSOFIA}

De acordo com a Lei n. 11.684/2008, mantendo a redação da LDB (BRASIL, 1996), em seu art. 35, na "etapa final da educação básica", o ensino de filosofia tem como finalidade: "preparação básica para o trabalho e a cidadania", com vista a "se adaptar com flexibilidade a novas condições de ocupação ou aperfeiçoamento posteriores"; o "aprimoramento como pessoa humana".

A cidadania, nos PCNEM (BRASIL, 1999, p. 48), é expressa em três dimensões distintas: estética, ética e política. A perspectiva estética, ou da sensibilidade, volta-se para questões de "natureza interna" e "se traduz na fluência da expressão subjetiva e na livre aceitação da diferença". Ela é expressão da capacidade de abertura para o outro, o diferente, a novidade etc.

Sobre o aspecto ético, ou identidade autônoma, a cidadania "deve ser entendida como consciência e atitude de respeito universal e liberdade na tomada de posição" (BRASIL, 1999, p. 49). Deste modo, ao viver sob certas normas em sociedade, deve-se estar disposto e ter liberdade para criticá-las. Ao julgar necessário, o procedimento deverá ocorrer sob bases orientadas por princípios universais igualitários.

E, finalmente, do ponto de vista político, ou da participação democrática, deve-se garantir o acesso de todos aos bens culturais e naturais existentes; o respeito às opiniões e aos estilos de vida de cada cidadão; e o engajamento concreto na construção de uma sociedade democrática (BRASIL, 1999, p. 49).

Entretanto, percebe-se, no Ensino Médio, uma tendência para uma educação pragmática e imediatista, voltada para conteúdos e metodologias práticas, que produzam resultados imediatos. Nesta perspectiva, os métodos e as técnicas tornam-se o fim da educação. Evidenciase no contexto escolar a emergência de um pensar em busca de resultados como a certificação do Ensino Médio para o ingresso no trabalho ou no ensino superior.

Nesse panorama, a importância da filosofia evidencia-se na sua contribuição potencial para que os educandos desenvolvam o pensamento criativo, reflexivo e intencional. Ou seja, a formação do pensar do educando deve ultrapassar o viés de utilidade que viabiliza resultados imediatos. 
Toda a teoria da educação em Dewey $(1959$, p. 2) aponta na restituição da aprendizagem ao caráter natural que ela tem na vida. Educação é vida, não preparação para a vida, o que pode significar que não se limita a fórmulas ou regras pedagógicas voltadas para uma formação para o trabalho. O que ocorre com a vida física e animal ocorre com a vida social. Esta se conserva através da educação: "assim se explica, com efeito, a continuidade de toda a experiência, por efeito da renovação do agrupamento social. A educação em seu sentido lato é o instrumento dessa continuidade da vida social".

Em seu conteúdo, o ensino de filosofia não deve ser desenvolvido como um produto acabado e cristalizado, mas deve estar aliado ao caráter dinâmico do conhecimento em que se manifesta a contradição do presente, o diálogo, a troca de saberes, enfim, o conhecimento escolar como processo. Neste sentido, a atitude do filosofar e o ensino de filosofia são dimensões da forma de compreender o homem e o mundo. Por essa razão, devemos evitar a dissociação destes polos ou a valorização de um deles.

No contexto atual, o ensino de filosofia emerge com a carência de práticas pedagógicas efetivas, no tocante a uma didática repensada para esse ensino, assim como urge a necessidade de definição de conteúdos quanto ao caráter conceitual, histórico, temático na área dos conhecimentos filosóficos.

Rodrigo (2009) e Gallo (2012) expõem discussões sobre metodologia e recursos didáticos relativos à orientação de determinados conteúdos filosóficos, articulados entre si e entre outros conteúdos, como aspectos formais da aprendizagem filosófica. Para desenvolver uma didática voltada para a facilitação do entendimento e aprendizagem, segundo Rodrigo (2009), caberia ao professor desenvolver operações de sínteses, esquematizações, reordenação e simplificação de conteúdo e linguagem atendendo sempre as demandas e considerando as características de cada turma.

Ainda segundo a autora, por meio da apresentação de textos auxiliares, que são caracterizados como um discurso "segundo" em relação ao discurso filosófico originário, além de outros recursos que também podem servir de instrumento facilitador da aprendizagem, como vídeos, músicas, poemas e desenvolvimento de debates, podem ser trabalhados conteúdos filosóficos apresentando o pensamento de teóricos, trazendo sempre o viés prático da filosofia, instigando-os a refletir questões do contexto atual e pessoal.

Ao abordar a metodologia do ensino de filosofia para o ensino médio, Gallo (2000) aponta que o caráter dialógico e a postura crítica podem ser encontrados em outros saberes. Entretanto, é apenas na filosofia que o pensamento conceitual se revela. $\mathrm{O}$ autor afirma que, se a identidade 
da filosofia está no ato da criação de conceitos e estes se referem a problemas, a discussão e a prática do ensino de filosofia deverá passar pelo conceito e pelo problema.

Em busca de um mapa conceitual, Gallo (2000) toma essa definição como princípio e problematiza o que é comum em aulas de filosofia no ensino médio: o estímulo à discussão e ao debate. Assim, o autor propõe uma "pedagogia do conceito", de modo que a aula de filosofia fosse um trato direto com os conceitos. A aula, segundo o autor, precisa ser vista como uma "oficina de conceitos", um local de trabalho, um laboratório, onde se façam experiências e experimentações com os conceitos.

Dessa forma, o fazer filosófico, na escola de ensino médio, deve desenvolver o exercício do pensar melhor, através da problematização e da indagação do presente, que permita ao estudante a criação e recriação de seus próprios conceitos e favoreça uma organização do pensamento para o enfrentamento do cotidiano, enquanto mundo de evidências, que nos faz crer como verdadeiro o que é aparente. Aqui a competência do professor, enquanto síntese de inúmeras experiências, faz a diferença.

\section{CONSIDERAÇÕES FINAIS}

Para despertar a própria natureza da atividade filosófica, o conteúdo filosófico, vivenciado no Ensino Médio, deve ser convertido em problematização acerca do mundo, visando a autonomia da capacidade de pensar e agir. Em "Filosofia - Construindo o Pensar", há destaque ao pensamento metafísico, ao serem expostos alguns temas como: "Ética entre o bem e o mal; "Deus entre a dúvida e a certeza"; "Amor como coisa do corpo e da alma", o que representa esforço por parte do professor no desenvolvimento desse conteúdo, visto que, se o livro se apresenta como um manual, histórico ou temático, deve estar engajado no contexto histórico-político e sua linguagem vinculada à realidade.

Nesse sentido, torna-se necessário desenvolver conhecimentos conceituais baseados na história da filosofia e não uma didática instrumental com o objetivo do mero "exercício do filosofar", o que revela a opinião e não a filosofia. Esses aspectos acarretam a criação de espaços de diálogo e análise críticos junto à realidade.

Essa reflexão implica na aproximação teoria e prática, de forma que tanto a prática quanto a teoria e seus pressupostos possam ser questionados. Nesse sentido, a teoria deixa de ser percebida como cânones que devem ser exemplarmente seguidos, e a prática deixa de ser pensada como algo "defeituoso" (como a experiência para os empiristas) que deve ser 
modificada pela força da teoria. Dessa forma, tanto os conteúdos filosóficos como a realidade passam a ser compreendidos como construção humana e não como algo pronto.

A instituição da Filosofia como disciplina no Ensino Médio deve possibilitar que o cotidiano, a vida, a prática, invada a escola, e venha a favorecer o pensar filosófico, a reflexão crítica sobre a própria prática. Se o impulso para a atitude filosófica é a admiração platônica ou o espanto aristotélico diante das coisas, temos, portanto, que nos voltar para a escola e olhar para ela com um novo olhar, procurar ver o que ainda não foi visto, procurar ver de um ângulo novo o que já vimos tantas vezes.

Não existe um modelo a ser seguido. Ensinar filosofia é um exercício diário que exige o perguntar filosófico e a atitude filosófica. Cabe ao educador comprometido com sua atividade não se apegar a receitas de manuais, que não contribuem para uma educação crítica, criadora e libertadora.

\section{REFERÊNCIAS}

ARANHA, M. L. de A.; Martins, M. H. P. Filosofando: introdução à filosofia. São Paulo: Moderna, 2009.

ARISTÓTELES. Ética a Nicômaco. 3. ed. São Paulo: Martin Claret, 2008.

BAPTISTA, M. G. de A. Gramsci e Vigotski: da educação ativa à educação crítica. João Pessoa: Editora Universitária da UFPB, 2012.

BRASIL. Resolução CNE/CEB $n^{o} 1$, de 18 de maio de 2009. Dispõe sobre a implementação da Filosofia e da Sociologia no currículo do Ensino Médio, a partir da edição da Lei ${ }^{\circ}$ 11.684/2008, que alterou a Lei no 9.394/1996, de Diretrizes e Bases da Educação Nacional (LDB). Ministério da Educação e Cultura. Brasília, DF. 2009. Disponível em: <http://portal.mec.gov.br/dmdocuments/resolucao_cne_ceb001_2009.pdf>. Acesso em: 10 ago. 2013.

Parecer $C N E / C E B n^{o} 22$, de 8 de outubro de 2008. Consulta sobre a implementação das disciplinas Filosofia e Sociologia no currículo do Ensino Médio.Secretaria de Educação Básica. Ministério da Educação e Cultura. Brasília, DF. 2008. Disponível em: <portal.mec.gov.br/cne/arquivos/pdf/2008/pceb022_08.pdf>. Acesso em: 10 ago. 2013.

. Lei $n^{\circ} 11.684$, de 2 de junho de 2008. Altera o art. 36 da Lei $n^{\circ} 9.394 / 96$, Lei de Diretrizes e Bases da Educação Nacional (LDBEN), para incluir a Filosofia e a Sociologia como disciplinas obrigatórias nos currículos do ensino médio. Presidência da República. Casa Civil. Subchefia para Assuntos Jurídicos. Brasília, DF. 2008. Disponível em: <http://www.planalto.gov.br/ccivil_03/_Ato2007-2010/2008/Lei/L11684.htm>. Acesso em: 20 set. 2013. 
Parecer $C N E / C E B n^{\circ} 38$, de 7 de julho de 2006. Inclusão obrigatória das disciplinas de Filosofia e Sociologia no currículo do Ensino Médio. Secretaria de Educação Básica. Ministério da Educação e Cultura. Brasília, DF. 2006a. Disponível em: $<$ http://professor.cee.ce.gov.br/index.php/espacodaaula/educacao-basica/file/1666-parecercne-ceb-n-38-2006-aprovado-em-7-de-julho-de-2006>. Acesso em: 10 ago. 2013.

Orientações Curriculares para o Ensino Médio. Ciências Humanas e suas Tecnologias. Secretaria de Educação Básica. Ministério da Educação e Cultura. Vol. 3. Brasília, DF, 2006b. Disponível em: <http://portal.mec.gov.br/secretaria-de-regulacao-esupervisao-da-educacao-superior-seres/195-secretarias-112877938/seb-educacao-basica2007048997/13558-politicas-de-ensino-medio>. Acesso em: 9 out. 2013.

Parâmetros Curriculares Nacionais para o Ensino Médio (PCNEM). Publicações. 1999. Disponível em: <portal.mec.gov.br/seb/arquivos/pdf/cienciah.pdf〉. Acesso em: 20 set. 2013.

Resolução CEB $n^{o}$ 3, de 26 de junho de 1998. Institui as Diretrizes Curriculares para o Ensino Médio. 1998. Disponível em: <http://portal.mec.gov.br/cne/arquivos/pdf/rceb03_98.pdf>. Acesso em: 6 jun. 2013.

. Parecer $C N E / C E B n^{\circ} 5$, de 7 de maio de 1997. Proposta de Regulamentação da Lei n. 9.394/96, Lei de Diretrizes e Bases da Educação Nacional (LDBEN). Conselho Nacional de Educação. Câmara de Educação. Ministério da Educação e Cultura. Brasília, DF. 1997. Disponível em: <http://portal.mec.gov.br/dmdocuments/ pcb0597.pdf>. Acesso em: 6 jun. 2013.

. Lei $n^{\circ}$ 9394, de 20 de dezembro de 1996. Lei de Diretrizes e Bases da Educação Nacional (LDBEN). Estabelece as diretrizes e bases da educação nacional. Brasília, DF. 1996. Disponível em: <http://www.planalto.gov.br/ccivil_03/ leis/19394.htm>. Acesso em: 20 set. 2013.

DEWEY, J. Democracia e Educação. 3. ed. São Paulo: Nacional, 1959. Experiência e Educação. 15. ed. São Paulo: Nacional, 1971

INCONTRI, D.; BIGHETO, A. C. Filosofia - construindo o pensar. São Paulo: Escala Educacional, 2008.

MARX, K.; ENGELS, F. A ideologia alemã. 10. ed. São Paulo: Editora Hucitec, 1996.

PALHANO, T. R. Pragmatismo, trabalho e educação: na Constituição de 1988. João Pessoa: Editora Universitária da UFPB, 2011.

RODRIGO, L. M. Filosofia em sala de aula - teoria e prática para o ensino médio. Campinas: Autores Associados, 2009.

ROSSI, W. Caminhos da Educação Socialista. São Paulo: Moraes, 1982.

TEIXEIRA, A. Introdução. In: DEWEY, J. Vida e Educação. 6. ed. Melhoramentos: São Paulo, 1973. 
VÁZQUEZ, A. S. Filosofia da práxis. 2. ed. Rio de Janeiro: Editora Civilização Brasileira S.A, 1968.

Data de recebimento: $11 / 04 / 2017$ Data de aceite: 01/11/2017 